\title{
Analisis Kontribusi Sektor Priwisata Terhadap Pendapatan Asli Daerah Kota Batu Periode Tahun 2011-2015
}

(The Analysis of Tourism Contribution to Local Revenue at Batu City

in 2011-2015)

Indah Puspitasari, Moh. Saleh, Duwi Yunitasari*

Ilmu Ekonomi dan Studi Pembangunan, Fakultas Ekonomi dan Bisni, Universitas Jember (UNEJ)

Jln. Kalimantan 37, Jember 68121

E-mail: duwiyunita.feb@unej.ac.id

\begin{abstract}
Abstrak
Tujuan penelitian ini adalah untuk mengetahui perkembangan pendapatan sektor pariwisata dan kontribusi sektor pariwisata terhadap Pendapatan Asli Daerah (PAD) di Kota Batu. Dalam penelitian ini digunakan data sekunder tentang perkembangan pendapatan pariwisata dan kontribusi pendapatan sektor pariwisata terhadap Pendapatan Asli Daerah (PAD) di Kota Batu. Penelitian ini dilakukan dengan menggunakan analisis kontribusi dan analisis trend (kecenderungan), bahwa perkembangan pendapatan pariwisata mengalami peningkatan selama kurun waktu 2011 - 2015. Berdasarkan hasil analisis dari penelitian ini menunjukan bahwa jumlah kunjungan wisatawan mengalami fluktuasi. Berdasarkan hasil analisis penelitian maka diperoleh hasil bahwa penurunan kontribusi sektor pariwisata tersebut diakibatkan karena kenaikan pendapatan sektor pariwisata diimbangi pula dengan kenaikan jumlah Pendapatan Asli Daerah (PAD) dari sektor-sektor lain dengan jumlah yang lebih besar.
\end{abstract}

Kata Kunci: Sektor Pariwisata, Pendapatan Asli Daerah (PAD)

\begin{abstract}
The main goal of this research is to determine the development of tourism revenue and the contribution of tourism sector to local revenue (LR) in Batu City. This research use secondary data on the development of tourism revenue and the contribution of tourism revenue to LR in Batu City. This research was conducted using contribution analysis and trend analysis, that development of tourism revenue increased during the period 2011 - 2015. Based of this research showed that the number of tourist arrivals has fluctuated. Based on the result of research analyzes the obtained result that the decrease in the contribution of the tourism sekctor resulting from the increase in tourism revenue are low by the amount of LR from other sectors with a larger amount.
\end{abstract}

Keywords: Tourism sector, local revenue

\section{Pendahuluan}

Setiap negara di dunia baik negara yang sedang berkembang maupun negara maju mutlak memerlukan pembangunan ekonomi. Pembangunan ekonomi perlu dilakukan untuk memperbaiki taraf hidup dan kesejahteraan masyarakat. Pembangunan ekonomi dapat dilakukan dengan memanfaatkan sumber daya yang dimiliki negara tersebut baik sumber daya alam atau manusia tanpa mengurangi perhatian terhadap aset lingkungan sekitar. Landasan utama pembangunan ekonomi suatu negara adalah stabilitas, kemerataan distribusi pendapatan (sesuai dengan proporsi masing-masing), pertumbuhan ekonomi yang dinamis dan neraca pembayaran yang seimbang serta efisiensi dalam segala bidang.

Indonesia menjadi salah satu negara berkembang tentu saja menpunyai cita-cita dan tujuan untuk meningkatkan kesejahteraan dan taraf hidup (sesuai dengan UndangUndang Dasar 45 alenia 4). Maka pembangunan perekonomian harus ditingkatkan dan dilaksanakan secara maksimal. Setiap pembangunan walaupun sekecil apapun pasti memerlukan dana apalagi membangun perekonomian negara besar Indonesia dengan jumlah penduduk sekitar 220 juta jiwa lebih. Terdapat beberapa sumber pendanaan pembangunan baik yang bersumber dari dalam maupun luar (Suparmoko, 1992:94).

\footnotetext{
* Corresponding Author
}

Pembangunan kepariwisataan terus ditingkatkan dan dikembangkan untuk memperbesar penerimaan devisa, untuk memeratakan kesempatan kerja usaha dan lapangan kerja, mendorong pembangunan daerah, meningkatkan kesejahteraan dan kemakmuran rakyat, memperkaya kebudayaan nasional dan tetap mempertahankan kepribadian bangsa serta tetap terpelihara nilai agama, mempererat persahabatan antar bangsa, cinta tanah air serta memperhatikan kelestarian fungsi dan mutu lingkungan hidup untuk pengembangan produk nasional (Soekadijo, 1997:26). Sektor pariwisata di Indonesia merupakan sektor industri yang sedang tumbuh dan berkembang. Berkembangnya pariwisata akan menimbulkan banyak segi positif, timbulnya industri kecil yang semuanya akan membawa kemakmuran bagi rakyat, sehingga dapat mengangkat bangsa Indonesia dalam kehidupan politik, sosial, ekonomi, dan kebudayaan yang lebih tinggi (Yoeti, 1990:115).

Pariwisata merupakan bagian penting dalam pembangunan ekonomi karena sektor pariwisata memiliki keterkaitan pada hampir semua subsektor ekonomi. Sehingga memberikan kontribusi pada perekonomian makro di Jawa Timur dan perekonomian di Indonesia. Pariwisata dapat memberikan dampak positif terhadap penerimaan devisa di Indonesia, memperluas lapangan pekerjaan, meningkatkan pendapatan masyarakat, daerah dan pusat serta sebagai wahana bagi 
masyarakat agar dapat memupuk rasa cinta tanah air sekaligus pengenalan budaya.

Leiper mengemukakan bahwa suatu daerah tujuan wisata adalah sebuah susunan sistematis dari tiga elemen. Seseorang dengan kebutuhan wisata adalah inti/pangkal (keistimewaan apa saja atau karakteristik suatu tempat yang akan mereka kunjungi). Seseorang melakukan perjalanan wisata dipengaruhi oleh faktor-faktor yang menjadi daya tarik yang membuat seseorang rela menghabiskan dana yang cukup besar. Suatu daerah harus memiliki daya tarik yang besar agar para wisatawan mau menjadikan tempat tersebut sebagai destinasi pariwisata (Pitana dan Gayatri, 2005:99).

Batu merupakan salah satu Kota yang terletak di provinsi Jawa Timur. Sebelum tahun 2001 Kota Batu adalah bagian dari Kabupaten Malang, kemudian ditetapkan menjadi kota administrativ pada Maret 1993. Pada tanggal 17 Oktober 2001, Batu ditetapkan sebagai kota otonom yang terpisah dari kabupaten Malang. Batu memiliki luas wilayah 202,30km² dengan memiliki ketinggian 700-1.700 meter di atas permukaan laut. Kota Batu terdiri dari tiga kecamatan yakni Batu, Bumiaji, dan Junrejo. Pariwisata di kota Batu merupakan salah satu yang terbesar di Indonesia bersamaan dengan Bali dan Yogyakarta (Hanas, 2012).

Pendapatan Asli daerah tidak lepas dari sumbangan pendapatan sektor pariwisata pada setiap tahun. Dapat kita lihat pada Tabel 1.2 bahwa pendapatan di sektor pariwisata mengalami fluktuasi pada setiap tahunya. Pada awal tahun 2011 pendapatan pariwisata di Kota Batu sebesar 3.57 milyar rupiah, dan pada tahun 2012 menurun pada angka 1.37 milyar rupiah. Namun seiring dengan perkembangan kepariwisataan di Kota Batu pendapatan sektor pariwisata mengalami kenaikan secara bertahap, pada tahun 2013 pendapatan sektor pariwisata meningkat pada angka 1.38 milyar rupiah. Pada tahun 2014 pendapatan pariwisata meningkat pada angka 4.12 milyar rupiah dan pada tahun 2015 meningkat menjadi 6.25 milyar rupiah.

Agar usaha pemerintah Kota Batu dapat berjalan baik sesuai program serta visi yang telah dibuat maka saat ini yang harus dilakukan adalah menjalin hubungan baik dengan para investor baik dalam maupun luar negeri yang menanmkan modal mereka pada industri pariwisata di Kota Batu. Hal tersebut dilakukan agar sektor pariwisata di Kota Batu dapat memberi kontribusi yang tinggi pada PAD Kota Batu dan mempercepat laju pertumbuhan ekonomi di Kota Batu.

\section{Metode}

\section{Rancangan atau Desain Penelitian}

Jenis penelitian ini adalah penelitian deskriptif. Penelitian deskriptif merupakan metode penelitian yang lebih memperhatikan pada fenomena yang bersifat actual pada saat penelitian dilakukan, kemudian di gambarkan dalam interpretasi yang rasional dan akurat (Nawawi, 2003). Penelitian kuantitatif adalah penelitian yang menekankan pada teori-teori melalui pengukuran variabel dengan angka dan menganalisis data dengan cara statistik (Indriantoro dan Supomo, 2002).

\section{Jenis dan Sumber Data}

Jenis data yang digunakan adalah data kuantitatif, yaitu data yang diperoleh dari objek penelitian dalam bentuk informasi angka. Data yang diperoleh dari Dinas Pendapatan Daerah, Badan Pusat Statistik Kota Batu, Dinas Kebudayaan dan Pariwisata Kota Batu dan Studi Pustaka. Penelitian ini dilakukan dengan membaca buku atau literatur yang berhubungan dengan penelitian ini. Dan dalam pelaksanaannya peneliti juga menggunakan literature yang ada.

\section{Metode Analisis Data}

1. Untuk mengetahui besarnya proporsi dan kontribusi dari sektor pariwisata terhadap pendapatan asli daerah, maka digunakan analisis proporsi dengan rumus (Djarwanto, 2001:152)

Dimana:

Z : proporsi penerimaan sektor pariwisata terhadap Pendapatan Asli Daerah

$\mathrm{Xm}$ : peneriman sektor pariwisata

Ym : Pendapatan Asli Daerah

2. Untuk mengetahui laju pertumbuhan nilai pendapatan dari sektor pariwisata, maka dapat digunakan rumus (Mulyadi, 2000:86)

Dimana:

Q : pertumbuhan nilai pendapatan sektor pariwisata

$\mathrm{Q}_{\mathrm{t}} \quad$ : nilai pendapatan sektor pariwisata tahun $\mathrm{t}$

$\mathrm{Q}_{\mathrm{t}-1} \quad$ : nilai pendapatan sektor pariwisata pada tahun $\mathrm{t}-1$

3.Untuk mengetahui laju pertumbuhan pengunjung wisata di Kota Batu maka dapat digunakan rumus (Mulyadi, 2000:86)

Dimana:

Q : pertumbuhan nilai pendapatan sektor pariwisata

$\mathrm{Q}_{\mathrm{t}} \quad$ : nilai pendapatan sektor pariwisata tahun $\mathrm{t}$

$\mathrm{Q}_{\mathrm{t}-1}$ : nilai pendapatan sektor pariwisata pada tahun $\mathrm{t}-1$

4. Untuk mengetahui prospek pendapatan sektor pariwisata digunakan model trend sebagai berikut, dengan rumus (Supangat, 2007:168)

$\mathrm{Y}=\mathrm{a}+\mathrm{bX}$

Dimana:

Y : Variabel Pendapatan Sektor Pariwisata

$\mathrm{X} \quad$ : Varibael waktu (Tahun)

a : Konstanta ( nilai $\mathrm{Y}$ pada saat $\mathrm{X}=0$ )

b : Kemiringan ( Koefisien perubahan nilai Y karena perubahan nilai $\mathrm{X})$.

\section{Hasil dan Pembahasan}

\section{Hasil}

Untuk mengetahui seberapa besar kontribusi pendapatan sektor pariwisata terhadap kenaikan Pendapatan Asli Daerah (PAD) di Kota Batu dapat menggunakan analisis proporsi yakni dengan membandingkan antara pemdapatan pariwisata dengan total Pendapatan Asli Daerah di Kota Batu. 
Tabel 1. Penerimaa nilai pendapatan sektor pariwisata di Kota Batu dalam kurun waktu $2011-2015$

\begin{tabular}{|c|c|c|c|}
\hline No Tahun & $\begin{array}{c}\text { Pendapatan } \\
\text { Sektor } \\
\text { Pariwisata }(\mathrm{Rp})\end{array}$ & $\begin{array}{c}\text { Penerimaan Total } \\
\text { PAD Kota Batu (Rp) }\end{array}$ & $\begin{array}{c}\text { Proporsi } \\
\text { Kontribu } \\
\text { si }(\%)\end{array}$ \\
\hline 1. 2011 & 3.571 .033 .728 & $30.257 .308 .053,14$ & 11,81 \\
\hline 2. 2012 & 1.377 .576 .373 & $38.794 .059 .670,38$ & 3,55 \\
\hline 3. 2013 & 1.381 .686 .971 & $59.670 .241 .826,89$ & 2,33 \\
\hline 4. 2014 & 4.125 .731 .961 & $78.288 .195 .526,04$ & 5,27 \\
\hline 5. 2015 & 6.250 .981 .784 & 104.397.289.394,10 & 5,99 \\
\hline \multicolumn{3}{|c|}{ Kontribusi Rata-rata } & 5,79 \\
\hline
\end{tabular}

Sumber : data diolah

Pada Tabel 1 menunjukan kontribusi penerimaan dari sektor pariwisata Kota Batu terhadap penerimaan PAD Kota Batu per tahun dari tahun 2011 - 2015. Dari Tabel diatas dapat diketahu bahwa secara keseluruhan dari tahun 2011 - 2015 kontribusi penerimaan PAD Kota Batu mengalami fluktuasi dari tahun ke tahun.

Kontribusi penerimaan PAD tertinggi Kota Batu tertinggi terjadi pada tahun 2011 yakni 11,81\% . Pendapatan sektor pariwisata terus mengalami fluktuasi di tiap tahunya. Pendapatan sektor pariwisata tertinggi yakni pada tahun 2015 yakni sebesar 6.250.981.784. Pada tahun 2012 pendapatan sektor pariwisata mengalami penurunan yakni menjadi sebesar 1.277.576.373 dan persentase sumbangan terhadap PAD sebesar 3,55\%. Pada tahun 2013 penerimaan sektor mengalami sedikit peningkatan menjadi 1.381.686.971 dan kontribusinya terhadap PAD sebesar 2,33\%. Pada tahun 2014 penerimaan sektor pariwisata mengalami peningkatan dari tahun sebelumnya dan peningkatanya cukup besar yakni 4.125.731.961 dan sumbanganya terhadap PAD sebesar $5,27 \%$. Pada tahun 2015 penerimaan sektor pariwisata mengalami peningkatan yang terbilang besar yakni sebesar 4.125.731.961. ini merupakan pendapatan yang paling besar diantara tahun-tahun sebelumnya namun, meskipun pendapatan sektor pariwisata mengalami kenaikan namun kontribusinya dalam PAD tidak terlalu besar, bahkan menurun dari tahun 2011 yakni sebesar 5,99\%. Penurunan yang terjadi lebih dikarenakan melemahnya sumbangan sektor industri jasa (Kepariwisataan) disbanding sektor lain yaitu sektor primer dan sekunder (BPS 2013).

Pertumbuhan nilai pendapatan sektor pariwisata Kota Batu selama periode 2011 - 2015 mengalami fluktuasi. Pendapatan sektor pariwisata Kota Batu tertinggi terjadi pada kurun waktu tahun 2015 yang mencapai nominal 6.250.981.784 milyar rupiah, sedangkan pendapatan sektor pariwisata terendah terjadi pada kurun waktu tahun 2012 yakni sebesar 1.377.576.373 milyar rupiah. Pertumbuhan pendapatan yang berfluktuasi ini dapat disebabkan karena jumlah kunjungan wisatwan yang naik turun setiap tahunya. Naik turunya kunjungan wisatawan dapat disebabkan karena pengaruh cuaca maupun perbaikan dan pembangunan yang terjadi di Kota Batu.
Tabel 2 Pertumbuhan nilai pendapatan sektor pariwisata di Kota Batu dalam kurun waktu 2011 - 2015

\begin{tabular}{llll}
\hline No. & Tahun & $\begin{array}{l}\text { Nilai Pendaptan } \\
\text { Pariwisata (Rp) }\end{array}$ & $\begin{array}{c}\text { Sektor Pertumbuhan } \\
(\%)\end{array}$ \\
\hline 1. & 2011 & 3.571 .033 .728 & $-62,85$ \\
2. & 2012 & 1.377 .576 .373 & 2,99 \\
3. & 2013 & 1.381 .686 .971 & 198,6 \\
4. & 2014 & 4.125 .731 .961 & 51,5 \\
5. & 2015 & 6.250 .981 .784 & \\
\hline
\end{tabular}

Sumber : data diolah

Pada Tabel 2 menunjukan perkembangan dan pergerakan nilai pendapatan sektor pariwisata di Kota Batu selama kurun waktu tahun 2011 - 2015. Pendapatan sektor pariwisata Kota Batu pada tahun 2011 sebesar 3.571.033.728 milyar rupiah dan mengalami penurunan pada tahun berikutnya yakni pada tahun 2012 sebesar -1,14\%. Pendapatan sektor pariwisata pada tahun 2012 yakni sebesar 1.377.576.373 milyar rupiah. Pada tahun 2013 pendapatan sektor pariwisata mengalami kenaikan sebesar 2,99\% dari nilai pendapatan sektor pariwisata tahun 2012 sebesar 1.377.576.373 milyar rupiah naik menjadi 1.381.686.971 milyar rupiah pada tahun 2013. Pertumbuhan nilai pendapatan sektor pariwisata mengalami kenaikan tertinggi pada tahun 2013-2014 yakni naik sebesar $198,6 \%$ dari nilai pendapatan tahun 2013 sebesar 1.381.686.971 milyar rupiah naik menjadi 4.125.731.961 milyar rupiah. Pada tahun 2015 pendapatan sektor pariwisata Kota Batu sebesar 6.250.981.784, merupakan pendapatan sektor pariwisata dengan nominal tertinggi selama kurun waktu 5 tahun yakni antara tahun 2011 - 2015. Penurunan pendapatan sektor pariwisata disebabkan adanya perbaikan beberapa tempat wisata di Kota Batu secara bertahap sehingga mengakibatkan pendapatan cenderung fluktuatif menurun.

Perbaikan infrastruktur dan pembangunan kepariwisataan yang dilakukan oleh pemerintah Kota Batu dapat menarik minat pengunjung wisata baik wisatawan domestik maupun mancanegara. Jumlah pengunjung wisata di Kota Batu sempat mengalami fluktuasi dan menuruh pada tahun 2011. Pada Tabel 3 ini akan ditunjukan laju pertumbuhan pengunjung wisata di Kota Batu selama kurun waktu 2011 2015.

Tabel 3 Pertumbuhan pengunjung sektor pariwisata di Kota Batu dalam kurun waktu 2011 - 2015

\begin{tabular}{cccc}
\hline No. & Tahun Jumlah Pengunjung & Pertumbuhan(\%) \\
\hline 1 & 2011 & 1.961 .559 & $-22,33$ \\
2 & 2012 & 1.603 .441 & 17,34 \\
3 & 2013 & 1.881 .446 & 11,03 \\
4 & 2014 & 2.089 .022 & 71,37 \\
5 & 2015 & 3.580 .000 & \\
\hline
\end{tabular}


Dari Tabel 3 dapat kita lihat bahwa pada tahun 2011 jumlah pengunjung sebanyak 1.961 .559 orang dan pada tahun 2012 mengalami penurunan sebesar $22,33 \%$, penurunan ini disebabkan oleh adanya pembangunan dan perbaikan dibeberapa tempat wisata tertentu seperti di tempat wisata Cangar, Songgoriti dan BNS. Pada tahun berikutnya yakni tahun 2013 jumlah pengunjung Kota Batu mengalami kenaikan sebesar 17,34\% dan berada pada jumlah 1.881 .446 orang. Kenaikan jumlah pengunjung juga terjadi pada tahun 2014 sebesar $11,03 \%$ dan berada pada jumlah 2.089 .022 orang. Pada tahun 2015 kenaikan jumlah pengunjung juga terjadi yakni sebesar $71,37 \%$ ini adalah angka fantastis yang diperoleh selama kurun waktu Batu menjadi Kota administratif. Pembangunan kepariwisataan yang terus dilakukan oleh pemerintah Kota Batu mebuahkan hasil yakni jumlah pengunjung yang besar pada tahun 2015 .

Perkembangan penerimaan sektor pariwisata selama kurun waktu tahun 2011 - 2015 mengalami fluktuasi namun cenderung meningkat mulai tahun 2013 sampai pada tahun 2015. Pada hasil analisis trend pertumbuhan penerimaan sektor pariwisata yang ada di kota Batu selama kurun waktu 2016-2020 menunjukan adanya kecenderungan kenaikan pendapatan. Pada tahun 2016 hasil trend penerimaan sektor pariwisata di Kota Batu sebesar 5.773.817.673 milyar rupiah, mengalami kenaikan pendapatan dari analisis trend pendapatan pariwisata di Kota Batu pada tahun 2015 yakni sebesar 4.963.012.503 milyar rupiah. Sedangkkan pada tahun 2017 hasil trend menunjukan bahwa estimasi penerimaan sektor Pariwisata di Kota Batu sebesar 6.584.622.843 dibanding tahun sebelumnya yakni pada tahun 2016, estimasi penerimaan mengalami peningkatan sebesar 14,04\%. Selanjutnya pada tahun 2018 hasil analisis trend menunjukan bahwa estimasi penerimaan sektor pariwisata Kota Batu sebesar 7.395.428.013, dari penerimaan tahun sebelumnya telah terjadi peningkatan penerimaan sektor pariwisata sebesar 12,31\%. Pada tahun 2019 hasil analisis trend menunjukan hasil estimasi penerimaan sektor parwisata di Kota Batu sebesar 8.206.233.183 dan mengalami peningkatan sebesar $10,96 \%$ dari penerimaan tahun sebelumnya yakni 7.395.428.013. Selanjutnya pada tahun 2020 terjadi peningkatan pendapatan sebesar $9,88 \%$, penerimaan sektor pariwisata pada tahun 2020 adalah sebesar 9.017.038.353.

Pada hasil analisis trend menunjukan bahwa terdapat peningkatan pendapatan disetiap tahunya namun pada segi pertumbuhan pendapatan mengalami penurunan. Hal ini dapat disebabkan oleh berbagai faktor yakni faktor manajemen Dinas Priwisata Kota Batu dalam mengelola pariwisata di Kota Batu. Peran Dinas Pariwisata sangat dibutuhkan dalam pengembangan pariwisata Di Kota Batu, pengembangan ini nantinya akan mempengaruhi pendapatan. Kegiatan promosi yang dilakukan oleh Dinas Priwisata selama ini sudah cukup bervariasi dan memiliki perencanaan yang baik, akan tetapi dalam pelaksanaanya masih terkesan setengah-setengah. Hal tersebut karena kurangnya komitmen dari pemerintah daerah dalam hal pemberian dana yang cukup dalam kegiatan promosi khususnya. Sehingga persoalan dana seringkali menjadi faktor penghambat dalam melakukan kegiatan periklanan karena besarnya dana yang dibutuhkan. Selain hal tersebut, yang menjadi kendala yakni 1)kualitas SDM dari Dinas Pariwisata yang belum semua mampu menguasai bahasa asing 2)sarana prasarana yang mendukung kurang memadai 3)Latar belakang pendidikan pegawai yang bukan berasal dari bidang pariwisata (Moses Yonathan:2012).

Segi kehidupan ekonomi nasional berkembangnya pariwisata akan menimbulkan segi positif yakni kemungkinan timbulnya industri kecil yang semuanya akan membawa kemakmuran bagi rakyat, sehingga akan dapat mengangkat bangsa Indonesia dalam kehidupan politik, social ekonomi dan kebudayaan yang lebih tinggi (Yoeti, 1990:115). Dari hasil analisis elastisitas penyerapan tenaga kerja pada sektor pariwisata dalam kurun waktu 2011 - 2015 menunjukan tingkat yang bervariasi. Dari hasil penelitian menunjukan bahwa tingkat elastisiatas terjadi pada tahun 2011-2012, 2012-2013 dan tahun 2014-2015. Pada tahun 2013-2014 sektor pariwisata menunjukan tingkat inelastic yakni $0,39 \%$.

Setiap kegiatan mempunyai daya serap berbeda terhadap tenaga kerja baik dalam kuantitas maupun kualitas. Daya serap tersebut berbeda secara sektoral dan menurut penggunaan teknologi. Sektor kegiatan yang dibangun dengan padat karya pada dasarnya dapat menciptakan kesempatan kerja yang relatif besar dan tidak terlalu terikat pada persyaratan ketrampilan yang tinggi. Sebaliknya sektor maupun sub sektor yang dibangun dengan padat modal menimbulkan kesempatan kerja yang relatif sedikit namun dipenuhi dengan kualifikasi tenaga trampil.. sehingga setiap kebijakan yang diambil pasti ada sisi positif dan negatifnya tergantung pada kondisi mana yang dipilih sesuai dengan karakteristik perekonomian di wilayah yang bersangkutan dan tujuan yang hendak dicapai (Simanjuntak, 1998:153).

\section{Simpulan}

Berdasarkan hasil penelitian dan analisis terhadap sektor pariwisata, selanjutnya dapat disimpulkan: 1) Perkembangan pendapatan sektor pariwisata cenderung meningkat. Jumlah pengunjung objek wisata pada tahun 2011 - 2015 mengalami kenaikan. Tepatnya pada tahun 2015 jumlah pengunjung Kota Batu mengalami kenaikan yang besar yakni sebesar $71,37 \%$ dan berada pada total jumlah pengunjung sebanyak 3.580.000 orang. 2) Kontribusi pendapatan sektor pariwisata terhadap PAD tahun 2011 - 2015 mengalami fluktuasi dari tahun ke tahun, hal ini menunjukan bahwa sumbangan sektor pariwisata terhadap Pendapatan Asli Daerah di Kota Batu pengaruhnya naik turun tapi cenderung turun sehingga perlu dilakukan pengembangan yang lebih baik lagi bagi pemerintah untuk meningkatkan pendapatan daerah dari tahun ke tahun yang akan datang.

\section{Referensi}

Andi, Supangat. 2007. Statistika Dalam Kajian Deskriptif Inferensi dan Nonparametrik. Jakarta: Kencana Penada Media Group.

Arsyad, Lincolin. 1997. Ekonomi Pembangunan. Yogyakarta: BPSTIE YKPN

Arsyad,Lincolin. 1999. Pengantar Perencanaan dan Pembangunan Ekonomi Daerah. Yogyakarta: BPFE.

Bramantio, Lynarsatia. 2000. Analisis Perkembangan Industri Pariwisata dan Pengaruhnya Terhadap Pendapatan Asli Daerah Surakarta 1990-2000. Universitas Sebelas Maret.

Due, Jhon F..1985. Keuangan Negara Perekonomian dari sektor Pemerintah. (Penerjemah Iskandarsyah dan Arif Javin. Jakarta(UI).

Djarwanto. 2001. Statistic Social Ekonomi: Bagian Pertama. Yogyakarta: BPFE

Gromang, Frans. 2003. Manajemen Kepariwisataan. Jakarta: Karya Grafis Digital 
Hanas, Imron. 2014. Mengembangkan Pariwisata Membangun Kota: Kota Batu 2001-2012

Hadari, Nawawi. 2003. Manajemen Sumber Daya Manusia Untuk Bisnis Kompetitif. Yogyakarta: UGM Press

Handayani, Dhina. 2012. Analisis Kontribusi Sektor Pariwisata Terhadap Pendapatan Asli Daerah Ngawi 2003-2010.

Hutabarat, R. V. 1992. Pengaruh Pengembangan Pariwisata terhadap Pembangunan Daerah Tapanuli Utara (studi pada Kawasan Wisata Pulau Samosir). Program pascasarjana, Institut Pertanian Bogor, Bogor.

Indriantoro dan Supomo. 2002. Metodolohi Penelitian Bisnis Untuk Aakuntansi dan Manajemen. Yogyakarta: BPFE.

Jhingan, M.L. 1994. Ekonomi Pembangunan dan Perencanaan. Jakarta : Raja Grafindo Persada.

Kartawan. 2000. Menumbumbuhkan Perekonomian Melalui Pertumbuhan Pariwisata. Universitas Siliwangi. Skripsi

Kodyat, H. 1982. Sejarah Pariwisata dan Perkembanganya di Indonesia. Jakarta: PT Gramedia Pustaka Utama.

Kodyat, H. 1996. Sejarah Pariwisata dan Perkembanganya di Indonesia. Jakarta: PT Gramedia Pustaka Utama.

Mangkoesoebroto, Guritno.1994. Kebijakan Publik Indonesia Substansi dan Urgensi. Jakarta. Gramedia Pustaka.

Munawir.1992. Analisa Laporan Keuangan. Edisi pertama Yogyakarta:Liberty

Mulyadi. 1998. Analisis Perkembangan Kependudukan menurut sensus penduduk: Dinamika Mobilitas Indonesia. Yogyakarta: Pusat Penelitian Kependudukan UGM.

Mulyadi.2000. Akuntansi Biaya. Yogyakarta: Aditya Media.

Nazara, Suahasil.1997. Struktur Penerimaan Daerah Propinsi-propinsi di Indonesia. Prima no.7.17.26.

Pitana, I Gde dan Gayatri, Putu G.2005. Sosiologi Pariwisata. Yogyakarta:Andi.
Rusli, Ghalib. 2005. Ekonomi Regional. Bandung: Pustaka Ramadhan.

Samsulridjal, dan Kaelany. 1996. Peluang di Bidang Pariwisata. Jakarta pusat: Mutiara sumber widya.

Simanjuntak, P. 1987. Ekonomi Sumber Daya Manusia dan Ketenagakerjaan. Yogyakarta: Graha Ilmu.

Simanjuntak, P. 1998. Ekonomi Sumber Daya Manusia. Jakarta: LPFE UI.

Sukirno, S. 1985. Ekonomi Pembangunan. Jakarta: LPFE UI.

Suparmoko. 1992. Ekonomika Pembangunan. Yogyakarta:BPFE.

Suparmoko. 1996. Ekonomika Pembangunan. Yogyakarta: BPFE.

Sutrisno, Hadi. 1991. Analisa Butir Untuk Instrument. Edisi pertama. Yogyakarta: Andi Ofset.

Suwantoro, Gamal. 2004. Dasar-dasar Pariwisata. Yogyakarta: Penerbit ANDI.

Soekadijo, R. G.1997. Anatomi Pariwisata. Jakarta: Penerbit PT Gramedia Pustaka Utama.

Spillane, J James.1987. Ekonomi Pariwisata Sejaran dan Prospeknya.Yogyakarta.

Spillane, J James. 1991. Ekonomi Pariwisata : Sejarah dan Prospeknya. Yogyakarta : Kanisius.

Spillane, J. 2001. Pariwisata Indonesia (siasat ekonomi dan rekayasa kebudayaan) Yogyakarta:Kanisius

Usman dan K. Subroto, SH.1980. Pajak-pajak Indonesia. Bandung: Yayasan Bina Pajak.

Wahab, Saleh.2003. Manajemen Kepariwisataan. Jakarta Pradnya Paramitha.

Wayong, J.1975. Administrasi Keuangan Negara. Jakarta: Ikhtiar.

Wing, Haryono.1978. Pariwisata Rekreasi dan entertainment. Ilmu Publisher: Bandung Perdana:2003:14.

Yoeti, A. Oka. 1990. Pengantar Ilmu Pariwista. Bandung : AKSARA 